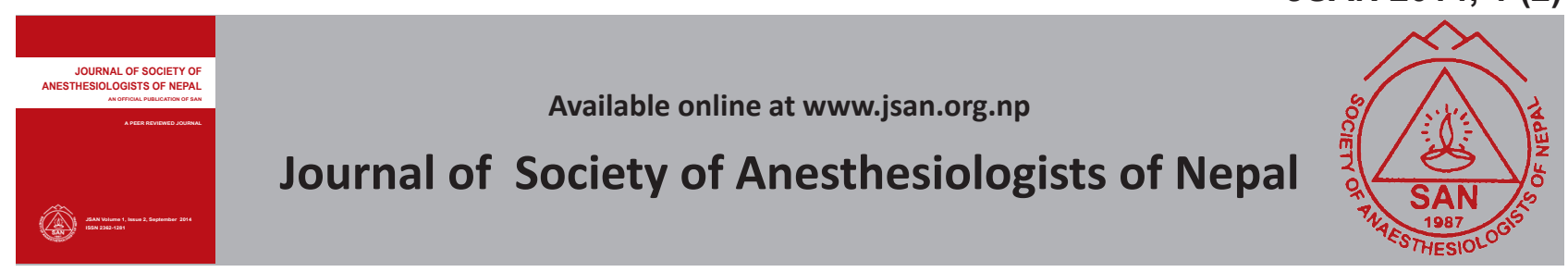

\title{
Editorial
}

\section{Critical Care Medicine: An emerging super specialty in Nepal.}

\author{
Subhash Prasad Acharya
}

Intensivist and clinical coordinator, Intensive Care Unit, Tribhuvan University Teaching Hospital,

Lecturer, Department of Anesthesiology, Institute of Medicine, Tribhuvan University, Kathmandu, Nepal

The term 'Intensive Care' refers to the great amount of care that a critically ill patient requires in comparison to a regular and less sick patient and the term 'Intensive Care Unit' refers to a separate ward in the hospital, which caters such sicker group of patients. The concept of Intensive Care was put forward by Florence Nightingale after the Crimean war when she started treating sicker patients in a separate area in the hospital and later, during World War II, these areas were established as 'shock wards' which were used to resuscitate and treat the injured soldiers. Following the Polio epidemic in 1952, Dr. Bjorn Aage Ibsen, a Danish Anesthetist, started the world's first Intensive Care Unit (ICU) in Copenhagen in 1953, when he treated respiratory paralysis of polio patients by intubating and ventilating them. ${ }^{1,2}$ At that time, there was already a three bed functioning postoperative ward for neurosurgical patients at the John Hopkins Hospital in the US since 1932, but this became the first multidisciplinary ICU only in 1958 and started providing care 24 hours a day. This was the first ICU to be covered by an in-site physician (anaesthesia resident) 24 hour a day and 365 days a year. ${ }^{2}$ Then after, ICU started flourishing all over the world with the advancement of modern technologies and electronic revolution, which made positive pressure mechanical ventilation better and easily available. At that time, ICU used to function as a multidisciplinary unit with involvement from various subspecialties, but basically run by Internal Medicine, Pulmonology, Cardiology or Anesthesiology. Since early 1990s, after the establishment of Critical Care Medicine, the branch of medicine that deals with the study of these critically ill patients, ICUs started functioning as a separate department. After that, a separate curriculum was introduced for teaching critical care in medical schools by almost all the universities in North America, Europe. Unfortunately this took another 20 years for ICUs to reach our part of the world.
In Nepal, before 1890s, Traditional medicine was the main form of medicine practiced and included Ayurveda, Faith $\&$ Spiritual healers and Naturopathy. Ayurveda could be traced as early as Vedic period (1500-800 BC) and uses Herbal Resources, Life style modifications as the main form of therapy. The year 1889 marked the beginning of Modern/Western medicine after the establishment of Prithvi Bir Hospital (now referred as National Academy of Medical Sciences, Bir Hospital). This was the first hospital to provide service and started with 30 Beds. ${ }^{4}$ This was the only hospital in the country for almost 60 years and as there were no doctors in Nepal, doctors from India were hired who worked till 1950s. A three years Proficiency Certificate Level Course in General Medicine was started for those who completed class ten or School Leaving Certificate (also referred to as Matriculation, Matric) and these persons were known as Health Assistants, who later served all over the country.

In 1951, after the end of autocratic Rana regime, few Mission Hospitals started serving the public. The first medical School, Institute of Medicine (IOM), was established in 1978 where Bachelor Course in Medicine was started. ${ }^{5}$ In1980, Tribhuvan University Teaching Hospital was established for the Clinical exposure to these students with the help from Japanese International Cooperation Agency (JICA). It is the largest tertiary referral center of the country till date. In 1993, BP Koirala Institute of Health Sciences, Dharan became the second Medical School of the country and in 1994, Manipal College of Medical Sciences, Pokhara was established as the First Private Medical College. ${ }^{5}$ Then after many more medical colleges and Institutions emerged totaling to 18 medical schools at present and another few are in the pipeline. Now, Private sector is much more involved in health service than Governmental service and covers $2 / 3^{\text {rd }}$ health service, and $3 / 4^{\text {th }}$ medical education. The health care is private and thus the patients have to pay

How to cite this article: Acharya SP. Critical Care Medicine: An Emerging super specialty in Nepal. JSAN 2014;1:55-58.

Corresponding author: Subhash Prasad Acharya

Tel.: +977-9851147242;

E-mail address:drsuvash@gmail.com 
for their healthcare, and unfortunately, there is no health insurance system.

In Nepal, the first ICU started in 1973 at Bir Hospital, as a five bed medical ICU. This ICU was established in 1970 when King Mahendra Bir Bikram Shahdev developed heart problem. ${ }^{5}$ King Mahendra was taken to India for treatment but after his return, he immediately ordered to create an ICU, which is still functioning in Bir Hospital as "The Old ICU". This was the only ICU in the country for almost 20 years. Another ICU became functional after the development of Tribhuvan University Teaching Hospital (TUTH) at Institute of Medicine (IOM), Maharajgunj in 1990 and was a six bed mixed medical surgical ICU. Immediately following this, TUTH added additional 5 bed Coronary ICU and 10 additional beds of high dependency units referred to as Intermediate Cardiac Care Unit (ICCU) and Surgical ICU. ${ }^{6}$ Then after, with the increasing demands of ICU beds, critical care slowly progressed and has now reached its present status.

Though the development of hospitals and ICUs in Nepal has progressed over the last decade, there are no definite data and publications to delineate the number of ICU beds and services outside the Kathmandu valley. There are no agencies to keep record of number of ICU beds and unfortunately the Ministry of Health does not have any data. Now almost all hospitals in the country have few 'ICU beds' accounting to a total of around 500 ICU beds in the country. The services, standard, outcomes and efficiency of these ICUs has rarely been published, except for very few hospitals. ${ }^{7,8}$ Till date, a single survey by Shrestha and colleagues has been published about ICU capacity and resources in Nepal. ${ }^{9}$ This was a survey of ICU within the Kathmandu Valley and included 51 hospitals from a list of ' $50+$ ' bed capacity obtained from Ministry of Health. Out of these, 11 (21.6\%) were Government Hospitals, 8 (15.7\%) were Community Hospitals and 32 (62.7\%) were Private Hospitals and only 33 (64.7\%) of hospitals have ICU facilities. There were 48 Intensive Care Units, with total of 331 ICU beds, which comprises of $4.7 \%$ of all hospital beds. Facility for mechanical ventilation was available only in 161 (2.3\%) of the total hospital beds. Considering population of around 20 million in 2011, there are only 15.2 ICU beds per 100,000 population and only 7.2 ICU beds with ventilator per 100,000 population. ${ }^{9}$ Most ICUs in Nepal are still functioning similar to ICU established by Dr. Dandy in 1958, without a 24 hours coverage by in-site physician. Around $37.5 \%$ of ICUs inside Kathmandu Valley have an in house coverage by Medical Officer (who is a graduate of Medical School but has not have entered into a formal postgraduate residency training program). ${ }^{6}$ At present, Nepal has specialized surgical services including cardiac surgery, neurosurgery, renal transplant and is also preparing to start liver transplant in recent future. Unfortunately, even with increasing demands of Critical Care Services, it is very slowly progressing and is clearly lagging behind the need. However, despite the limited resources, there are few publications on smaller studies conducted in ICUs in Nepal. ${ }^{10-16 .}$

The term 'ICU' in Nepal refers to a separate area in the hospital identified to admit critically ill patients requiring life support including inotropes/vasopressors and/or mechanical ventilators. However, there are no governing bodies to monitor the services, quality and facilities required to run an ICU. ${ }^{6}$ Recently, a workshop was conducted in July 2014 by Nepalese Society of Critical Care Medicine (NSCCM) in collaboration with Ministry of Health which has planned to accredit ICUs based on their facilities as Level I, II, and III. After the workshop, the president of the society, Prof. Moda Nath Marhatta, made recommendation to the Ministry of Health to work in collaboration with NSCCM to develop certain Level ICUs in District, Zonal Hospitals and Tertiary Centers. They also recommended for a governing body for accreditation of these ICUs. ${ }^{17}$ NSCCM has also been conducting various CMEs and training in the country in the field of critical care. An international conference is being organized in collaboration with association of SAARC critical care societies in November 2014. ${ }^{17}$

Almost all ICUs in Nepal are 'Open ICUs' and currently Internist and Anaesthesiologists are managing patients. Anesthesiologists are called in for Mechanical Ventilation, Vascular Access, Hemodynamic Monitoring and lonotropes/Vasopressors whereas other areas are taken care by Internist or Surgical specialty whosoever the primary attending consultant is. Though, numerous literatures have supported the advantages of closed ICUs and their benefits over open ICUs especially in a poor country like Nepal, because of lack of certified Intensivist in the country, there are only three Closed ICUs in Nepal. The first closed ICU is at BP Koirala Institute of Health Sciences (BPKIHS), Dharan, which is managed by the Department of Anesthesiology since 1994 and the other two are in Private Hospitals in Kathmandu since 2013 only. ${ }^{9,12,15}$ Thus it seems that the concept of closed ICUs is emerging and is being recognized by newly developed hospitals in Nepal. This is also because there are around ten Intensivists who have completed their training in Critical Care either from India or abroad and are currently working in Nepal. This has been possible because of some Universities in Canada and some institutions in India are offering a one-year international fellowship program for specialist physicians who want training in Critical Care medicine but will return back to their country. Dr. Gentle Sunder Shrestha completed his one-year Fellowship and currently Dr. Diptesh Aryal is currently pursuing his Fellowship in Critical Care Medicine at St Michael's Hospital, at the University of Toronto. These programs have helped a lot to improve human resources and develop Critical Care Medicine in developing countries like Nepal. European Diploma of Intensive Care (EDIC) can also be an option for training of Intensive Care in Nepal as this program has two level exams and the training can be done in centers in India. 
As Nepal is going through a process of political reform and stabilization after a ten year long civil war, the medical education cannot remain untouched. On one hand, because of presence of only few Intensivists, the country and healthcare system demands more number of trained Intensivists to manage critically ill patients not only inside Kathmandu but to manage around 100 ICUs in all across the country. On the other hand, it's a pity that Universities and Nepal Medical Council do not recognize the Fellowship degrees and Diplomas that are awarded/ recognized by Universities/Societies from around the world. They only entertain the postgraduate super specialty programs that are based on the Indian system, the Doctorate of Medicine (DM), which is a more longer duration program. Thus, if the Universities and the Nepal Medical Council remains stringent on their rules of training duration and their requirement of preceptors/mentors of these academic programs, training for three years for a super-specialty and producing two DM Candidates per year will take another hundred years to fulfill the need of the country. So, the Nepal Medical Council and Universities should adapt to a policy where they accept these trained Fellows as preceptors/instructor of academic programs for certain years till we have adequate DM specialists, who then will be the preceptors of the academic training program. In a DM program, a candidate after completing his medical school and his postgraduate specialization (at least three years) faces a competitive entrance exam on a merit basis and gets entry. Once into the super specialtytraining program, the candidate works as a Fellow/ DM Resident for three years and also does a dissertation/ thesis writing after which he becomes eligible to sit for the Final Evaluation by the University. Once this evaluation is complete and the candidate clears the exam, he will be awarded the Doctorate of Medicine (DM) degree in the respective field. The degree/program is called Master of Chirurgery (MCh) for surgical superspecialities. ${ }^{18}$ If we consider the immediate need of country, we need a much shorter duration training programs ( $4-6$ weeks) at present to teach early management, stabilization and proper early transfer to higher center especially targeted for Medical Officers, Residents, General Practitioners working in the rural areas and district hospitals.

Academic training in Critical Care Medicine was a dream till 2012 as there were no academic training programs in Critical Care Medicine in Nepal. Recently, a super specialty DM training program in Critical Care Medicine, has been started at IOM, Tribhuvan University (TU) from October 2013 after a formal collaboration with Royal College of Physicians and Surgeons of Canada (RCPSC) in May 2013. ${ }^{19}$ As there is a clear lack of instructors and resources, the Royal College of Physicians and Surgeons of Canada is supporting in terms of providing instructors and mentors for the program till the program becomes self-sustainable. The DM Critical Care Medicine program (DM CCM) at IOM is based on the CanMeds Framework which is based on the seven roles that all physicians need to have, to be better doctors: Medical Expert, Communicator, Collaborator, Manager, Health Advocate, Scholar, and Professional. ${ }^{20}$ Since there is no separate Department of Critical Care Medicine at the Institute of Medicine, the DM Critical Care Medicine is being run by a DM CCM Program Coordination committee, which is headed by Professor of Anesthesiology, Prof. Roshana Amatya and other members which includes the Professor and Head of Department of Anesthesiology, Cardiothoracic and Vascular Surgery, General Practice and Emergency, General Surgery, Internal Medicine, and Pediatrics. Dr. Laura Hawryluck and Dr. Redouane Bouali are the project directors who have directly involved in curriculum development and training of the DM Residents since the inception of the program. ${ }^{19}$ Unlike other developed countries, the eligibility for entry into DM CCM has been broadened to encompass other specialties like MD General Practice and Emergency, MD General Surgery, MD Pediatrics in addition to MD Anesthesiology and MD Internal Medicine with a view to get more candidates trained for the country which is the need of time. Till date, the first batch has only one DM candidate and second batch has two DM Residents enrolled in the DM CCM program, which is also disheartening because the University cannot enroll more than two DM Residents per year as per the criteria laid by the Nepal Medical Council.

Another DM program in Pulmonology, Critical Care and Sleep Medicine, was started in Bir Hospital NAMS, in 2012 based on a similar program in one institute in India, PGI Chandigarh. This program was stopped in 2014 because of unavailability of preceptors at NAMS but is again introduced at BPKIHS, Dharan in 2014. ${ }^{9}$ The DM in Pulmonology, Critical Care and Sleep Medicine being a combined program, does not encompass all aspects of critical care and the curriculum covers only the respiratory components and leaving behind a massive chunk of critical care like surgical critical care, hemodynamic monitoring, vascular access, trauma and polytrauma, toxicology etc.

As Critical Care Medicine has emerged as a super-specialty, development of Department of Critical Care Medicine, Intensivist managed Closed ICUs, and increasing the number of these super-specialty training programs (DM or Fellowship) in Critical Care Medicine is a necessity. It is the need of time to improve the quality and standard of care in our ICUs with facilities and the stakeholders should also work toward improving access to critically ill patients from rural areas in a poor and developing country like Nepal.

Conflict of Interest Statement. The author has no potential conflicts of interests.

\section{References}

1. Berthelsen PG, Cronqvist $M$. The first intensive care unit in the world: Copenhegan 1953. Acta Anaesthesiol Scan 2003;47:11901195.

2. Pincock S. Bjorn Aage Ibsen. The Lancet. 2007; Vol. 370 (9598): p 1538.

3. Bleck T. Historical aspects of critical care and the nervous system. 
Crit Care Clin 2009;25:153-64.

4. Dixit H. Medicine in Nepal. J Nep Med Assoc 1974;12;43.

5. Marasini B R. Health and Hospital Development in Nepal, Past and Present. JNMA 2003;42:306-311.

6. Critical Care medicine in Nepal: where are we? Acharya SP. International Health 2013;5:92-95.

7. Sharma NR. Outcome of intubated post-surgical cases in intensive care unit in Tribhuvan university teaching hospital, Nepal. Journal of Institute of Medicine 2005;27:155-157.

8. Koirala S, Ghimire A, Sharma A, Bhattarai B. ICU admission and outcomes in a community-based tertiary care hospital: an audit of one year. Health Renaissance 2011;9:83-87.

9. Shrestha RR, Vaidya PR, Bajracharya GR. A survey of adult intensive care units in Kathmandu Valley. Postgrad Med J NAMS. 2011;11:1-7.

10. Lakhey S, Karki B, Shrestha B, Shakya S, Pandey SB. Sepsis: a private hospital experience in Nepal. Journal of Institute of Medicine 2006;28:8-11.

11. Shankar PR, Partha P, Dubey AK, Mishra P, Deshpande VY. Intensive care unit drug utilization in a teaching hospital in Nepal. Kathmandu Univ Med J 2005;3:130-7.

12. Joshi S, Agarwal B, Malla G, Karmacharya B. Complete elimination of tetanus is still elusive in developing countries: a review of adult tetanus cases from referral hospital in Eastern Nepal. Kathmandu Univ Med J 2007; 5:378-81.

13. Acharya SP, Pradhan B, Marhatta MN. Application of "the Sequential Organ Failure Assessment (SOFA) score" in predicting outcome in ICU patients with SIRS. Kathmandu Univ Med J 2007;5:475-83.

14. Shrestha GS, Gurung R, Amatya R. Comparison of Acute Physiology, Age, Chronic Health Evaluation III score with initial Sequential Organ Failure Assessment score to predict ICU mortality. NMCJ 2011;13:50-4.

15. Joshi S, Agrawal B, Deo G P, Bhattarai B K, Rahman T R, Biswas B K. Percutaneous dilational tracheostomy: an initial experience in community based teaching hospital. Kathmandu Univ Med J 2006;4:275-80.

16. Shrestha GS, Shrestha PS, Acharya SP, Sedain G, Bhandari S, Aryal D, et al. Apnea testing with continuous positive airway pressure for the diagnosis of brain death in a patient with poor baseline oxygenation status. Indian J Crit Care Med 2014; 18:331-3.

17. Nepalese Society of Critical Care Medicine (NSCCM). Available at: www.nsccm.org. Accessed on 15 August 2014.

18. Medical Council Of India: Post Graduate Medical Education Regulations 2000. Available at: http://www.mciindia.org/ RulesandRegulations/PGMedicalEducationRegulations2000.aspx. Accessed on 15 Aug 2014.

19. Royal College of Physicians and Surgeons of Canada. Fellows help establish Nepal's first Critical Care training program. Available at: http://www.royalcollege.ca/portal/page/portal/rc/resources/ publications/dialogue/vol14_3/training_in_nepal. Accessed on 15 Aug 2014.

20. Royal College of Physicians and Surgeons of Canada. The CanMedS Framework. Available at: http://www.royalcollege.ca/portal/page/ portal/rc/canmeds/framework. Accessed on 15 Aug 2014. 